\title{
Functionalism and thinking animals
}

\author{
Steinvör Thöll Árnadóttir
}

Received: 16 December 2007/Accepted: 14 October 2008/Published online: 5 November 2008

(C) Springer Science+Business Media B.V. 2008

\begin{abstract}
Lockean accounts of personal identity face a problem of too many thinkers arising from their denial that we are identical to our animals and the assumption that our animals can think. Sydney Shoemaker has responded to this problem by arguing that it is a consequence of functionalism that only things with psychological persistence conditions can have mental properties, and thus that animals cannot think. I discuss Shoemaker's argument and demonstrate two ways in which it fails. Functionalism does not rid the Lockean of the problem of too many thinkers.
\end{abstract}

Keywords Personal identity - The problem of too many thinkers · Functionalism · Lockeanism · Sydney Shoemaker

Sydney Shoemaker (1999a, 1999b, 2004, 2008) has proposed a functionalist solution to a problem of too many thinkers that arises for Lockean accounts of personal identity. Lockeans claim that persons have psychological persistence conditions and, given that animals do not have psychological persistence conditions, they must deny that persons are identical to animals. But such a denial becomes problematic when it is combined with the very plausible assumption that animals share the thoughts of the persons they constitute. If wherever there is a thinking person there is a thinking animal distinct from it, then there are at least twice as many thinkers as we thought there were-hence the problem of too many thinkers. Most will find this consequence preposterous, and some take it to be an excellent reason for rejecting Lockeanism and affirming our identity with "our" animals (e.g. Snowdon 1990; Olson 2003). Others, including Shoemaker, take it as a reason for denying that our animals can think.

S. T. Árnadóttir $(\bowtie)$

University College London, London, England

e-mail: steinvortholl@gmail.com 
This latter move is not prima facie appealing. Our animals would appear to share with us all the features relevant to having thoughts. They have the same brains and nervous systems, the same perceptual systems, the same environmental inputs and the same behavioural outputs, to name but a few. So how could they fail to think? Shoemaker's answer is that animals have the wrong persistence conditions to think. It follows from the functionalist nature of properties that what properties a thing can have depends partly on what sort of persistence conditions the thing has, and Shoemaker argues that "mental properties, and whatever physical properties same-subject determine them... can belong only to things having psychological persistence conditions" (Shoemaker 2004, p. 528).

Shoemaker's proposal is of particular interest as property functionalism is an independently motivated and plausible thesis. If it really had the consequence that animals cannot think, this would provide much needed support for Lockeanism. Unfortunately for the Lockean, it does not. Although it is true that there is a dependency relation between what properties a thing can have and its persistence conditions, there is little reason to believe that this dependency is such that mental properties can only be had by things with psychological persistence conditions. After outlining the core tenets of Shoemaker's position and his argument for why animals cannot think, I propose two different ways in which his argument fails to establish its intended conclusion.

\section{1}

The central claim of Shoemaker's functionalism is that properties are individuated by the conditional causal powers they bestow on their bearers (see e.g. Shoemaker 1980/2003). If we call the entirety of conditional powers bestowed by a property its causal role, we can make the point by saying that $\mathrm{P}$ and $\mathrm{P}^{*}$ are the same property if and only if they have the same causal role. Expanding slightly, to have a conditional causal power is to be liable to bring about certain successor states in certain circumstances. Thus, $\mathrm{P}$ and $\mathrm{P}^{*}$ have the same causal role, and so are the same property, if and only if their instantiation will result in the same successor states under all possible circumstances. This is the crucial idea behind Shoemaker's argument against animal thought.

The second idea on which Shoemaker's argument rests is that it is definitive of the causal role of some properties that their instantiation will bring about certain successor states in their bearer:

[T]here is an internal relation between what properties an individual can have and what its persistence conditions are. This is because the causal powers which the properties of a thing jointly bestow on it are individuated in part by how their manifestation will influence the future career of that very thing. (Shoemaker 2003, p. 4, my italics.) 
I will call properties that stand in an internal relation of this sort to their bearer's persistence rich properties. ${ }^{1}$ Mental properties are primary examples of rich properties, and other rich properties include various dispositional properties such as elasticity.

Something is elastic just in case it, that same thing, will change shape when certain forces are applied, and then revert to its original shape when the forces are removed-it is constitutive of something's being elastic that its future career will go a certain way under certain conditions ... similar points apply to other dispositional properties, and they apply as well to the properties in which these properties are realized. (Shoemaker 2008, pp. 316-317.)

Similarly, the potential successor states definitive of mental properties must be states of the bearer of the property, and the specification of the causal roles of such properties must make reference to what will happen to the bearer of the property, given that certain other properties are instantiated by the bearer, under certain conditions. Thus, for instance, my desire to drink will, all other things equal, result in $m y$ drinking, if $I$ also believe I can drink, and that my desire stands in these relations to my other drink-related states and actions is partly constitutive of its being a desire to drink.

Shoemaker's argument against animal thought runs as follows. Given the difference in the persistence conditions of animals and persons, there will be certain conditions under which the animal and the person can come apart, such that each might continue to exist without the other. Under such conditions, the person's mental properties and the animal's supposed mental properties will not have the same successor states or actions. But that means that the alleged mental properties of the animal and the bona fide mental properties of the person differ in their causal roles. And so, given that properties are individuated by their causal roles, they cannot be the same properties. This is a restricted version of the more general argument contained in the following passage, which I will call the causal roles argument:

If there can be coincident objects which have different persistence conditions, there will have to be a difference in the properties of these things corresponding to a difference in their persistence conditions. Suppose that A and $\mathrm{B}$ coincide, but that their persistence conditions differ in such a way that under condition $\mathrm{C}$ they will cease to coincide and will go their separate ways. If the powers of $\mathrm{A}$ dictate that under condition $\mathrm{C}$ the possessor of these powers will have such and such properties and such and such a spacetime trajectory,

\footnotetext{
${ }^{1}$ In places, Shoemaker gives a very similar characterisation of what he calls thick properties, but his notion of a thick property is stronger than the notion of a rich property just given. Thus, Shoemaker builds it into the notion of a thick property that it cannot be shared by objects with different persistence conditions (e.g. 2003, p. 1), and this does not follow from richness alone.
} 
obviously these powers, and the properties that bestow them, cannot all be shared by B. (Shoemaker, 1999a, p. 298.)

We can take the supposed scenario here to correspond to familiar brain transplant scenarios. Imagine that a person's brain is transplanted into another animal in such a manner that the thought processes it supports go on interrupted and the person whose consciousness and mental life is supported by the brain after the transplant is perfectly psychologically continuous with the person whose consciousness and mental life it supported before the transplant. The Lockean reading of such a scenario is that the person 'goes with' the brain and leaves its animal behind. Assuming for the sake of argument that this is correct, we can assume also that the mental states of the person before transplant will continue after transplant to generate the successor states that are definitive of their being the states they are.

Let us suppose, for instance, that prior to the transplant the person was thinking through some argument premises and that after the transplant her reasoning results in her drawing a conclusion suitable to her thinking about these premises. Or imagine that just prior to the transplant the person realised she could afford to go on a holiday, and that after the transplant she is appropriately excited and starts pondering where to go. Although it might have appeared that before the transplant the animal was following the same reasoning and having the same realisations about potential upcoming holidays, the thought runs, this can now be seen to be a misperception. The animal's alleged reasoning does not result in its drawing a conclusion, nor does the idea of a holiday excite it. Instead it just lies there after the transplant, stripped of thought and emotion, instantiating none of those successor states typically constitutive of the having of mental states. If you're tempted to respond that the person's post transplant states are successor states to the animal's states too, be reminded that mental properties and whatever properties realise them are rich properties, such that their appropriate successor states must belong to the same thing. As such, the post-transplant person's states couldn't be appropriate successors to the animal's mental states. Shoemaker thinks such considerations show that animals cannot have mental properties.

\section{3}

One might worry that functionalism does not in itself commit one to a Lockean reading of brain transplant scenarios and so the argument must rely on Lockean assumptions about the persistence conditions of persons (e.g. Olson 2002). But this is not my worry. If functionalism plus Lockeanism entailed that animals cannot think, that would be important enough. And as I am concerned here with whether functionalism can be employed to defend Lockeanism, and not with how Lockeanism might be established, I am happy to assume here that the Lockean reading is correct. Further, I do not wish to challenge the functionalist thesis that properties are individuated by their causal roles, nor indeed the observation that many, if not most, properties stand in an internal relation of sorts to their bearers persistence conditions. I think we can grant all of this and still not be moved to the conclusion that animals cannot think. 
I have two responses to Shoemaker's argument. The first response grants that the argument establishes that animals' mental properties would have to be slightly different from those of persons, but denies that this has the consequence that animals cannot think. The second response grants that there are possible scenarios in which the mental properties of the animal and the person do not bring about the same successor states, but denies that it follows from this that their properties differ. I discuss each in turn.

\section{4}

Assume for the moment that Shoemaker's argument establishes that the causal roles of the alleged mental properties of animals must be different from the causal roles of the mental properties of persons. Assuming also that properties are individuated by their causal roles, it follows from this that animals cannot have exactly the same mental properties as the persons they constitute. It does not follow from this alone, however, that animals cannot have any mental properties. They might rather have slightly different mental properties from persons; the sort that belongs to animals rather than persons and as such do not bring about appropriate successor states in the imagined brain transplant scenario. Indeed, given that the causal roles of the alleged mental properties of animals will otherwise be exactly like those of the mental properties of persons, this seems like the right thing to say. And, moreover, this is precisely the sort of claim that a defender of the causal roles argument will have to make with regards to non-mental properties if he is to save the argument from the following reductio.

The causal roles argument, recall, is a general argument. Assuming that it does work, we may conclude that any property of the animal that has a successor state under the brain transplant condition must have a different causal role from any property of the person that does not have such a successor state under that condition. And this will include all of the animal's biological properties, (save perhaps some having to do with a part of the brain), as well as any physical properties that realise those. So if we are to take it that the causal roles argument entails that animals do not have mental properties, then we ought similarly to conclude that persons do not have any biological properties nor indeed any biology realising physical properties. And this ought to strike most people as a reductio of the position. ${ }^{2}$ It thus transpires that unless, perhaps, you are willing to embrace immaterial souls, you cannot accept the causal roles argument without some complementary method for cost-reduction.

The obvious manoeuvre here is to claim that persons do have biological properties, they just have slightly different biological properties from their animals; the sort that belong to persons rather than animals and that as such do not bring about appropriate successor states in the imagined brain transplant scenario. And indeed, this is precisely what Shoemaker himself says. Acknowledging that it is

\footnotetext{
${ }^{2}$ See Olson (2002) for a complaint along these lines, though his construal of Shoemaker's argument, as well as his response to it differ significantly from the ones given here.
} 
'surely unacceptable' to deny that persons have biological properties, he claims we ought rather conclude that persons have slightly different biological properties.

[T] he transfer of my cerebrum to a different body ... might lead to my losing my immunity ... while my present biological animal, left behind as a human vegetable, would retain its immunity. ... So immunity to smallpox in persons has a slightly different causal profile than immunity to smallpox in biological animals, and these are arguably slightly different properties. (Shoemaker 2008, p. 323.)

Shoemaker thinks that the correct conclusion is that persons have slightly different biological properties from animals rather than that they have no biological properties. And not only does he think this, he also claims that this strategy allows us to "still hold that persons have all of the kinds of physical properties we take them to have" (Shoemaker 2008, p. 324).

It may be that biological predicates that are applicable to human animals are applicable as well to persons, but that they have slightly different senses, and ascribe slightly different properties, in the two sorts of applications. (Shoemaker 2008, pp. 322-323.)

This seems to me a sensible suggestion. The only trouble is that a precisely analogous manoeuvre would seem to recommend itself in the case of mental properties. Shoemaker acknowledges as much, but adds that "this would play havoc with my solution to the too many minds problem and seems to me to have nothing to recommend it" (Shoemaker 2008, p. 323). But it seems to me that this manoeuvre does indeed have something to recommend it. First, hypothetical separations from their persons aside, animals would appear to fulfil all the criteria for having mental properties that their persons do. So there is a positive reason for thinking that animals do indeed have mental properties. Second, the case of biological properties and the case of mental properties seem relevantly similar to warrant analogous moves, and as such one would seem to need a reason for not making the suggested move in the mental case, given that one makes it in the biological case. But aside from causing havoc with Shoemaker's proposal, it is not at all clear what might count against it.

I conclude that even if we do grant Shoemaker that the mental properties of persons and animals would have to differ slightly, there is no obvious reason why we ought not say that animals and persons do nonetheless satisfy all the same mental predicates, and animals have all the kinds of mental properties we take them to have.

\section{5}

I think we can go further. We need not grant Shoemaker that the mental properties of persons and animals must differ at all, even assuming that functionalism is true and brain transplants are correctly given a Lockean reading. Lockean assumptions granted, what the brain transplant scenario shows us is that under brain transplant 
conditions the mental states of the person bring about successor states in the person that the animal's supposed mental states fail to bring about in the animal. But that in itself does not entail that the properties must differ in their causal roles. For that follows only if it is also the case that the condition under which one state generates a successor is the same as that under which the other state fails to generate a successor.

According to functionalism, if it is constitutive of a property $\mathrm{P} 1$ that it brings about a successor state SS under certain circumstances $\mathrm{C}$; then if P2 does not bring about successor state SS under those very same circumstances C, then P2 is not P1. But why should we think that the circumstances of the animal and of the person are the same in a brain transplant case? Applying the causal roles argument to mental state realisers, Shoemaker claims that:

Given that the persistence conditions of the human animal allow it to become a human vegetable through the transplantation of its cerebrum to another body, the property of the human animal expressed by the predicate 'has a cerebrum in physical condition $X^{\prime}$ cannot bestow the same conditional causal powers as the property of the person expressed by that same predicate. (1999a, p. 301, my italics).

So, let us follow Shoemaker in taking 'transplantation of its cerebrum to another body' to pick out our test condition. It is true that under this condition, the properties of the animal and the properties of the person will not result in the same successor states. But that only shows that the properties differ in their causal roles if 'transplantation of its cerebrum to another body' picks out the same condition for the animal and the person. And there are good reasons to doubt this.

Shoemaker claims that the difference in successor states to 'having cerebrum in state $\mathrm{X}$ ' in the animal and the person under the condition of 'transplantation of its cerebrum to another body' shows that 'having cerebrum in state $X$ ' picks out different properties when applied to animal and person. But it seems at least as plausible to say that 'transplantation of its cerebrum to another body' picks out different conditions for the animal and the person, and that prior to the transplant the animal and the person 'have a cerebrum in state $\mathrm{X}$ ' in much the same sense. Indeed, there are quite different things involved for the animal and the person in having their cerebrum transplanted to a different animal. On the one hand, as far as the animal is concerned 'transplantation of its cerebrum to another body' involves it having its cerebrum detached from itself and moved into a different body. On the other hand, where the person is concerned, 'transplantation of its cerebrum to another body' involves it having a whole body and lower brain transplant. It is very far from obvious that this is the same condition. It seems plausible that not only is there a difference between these conditions, but that it is precisely the sort of difference required for explaining why the animal's states and the person's states fail to bring about the same successor states. Indeed, it is hard to think of a better excuse for not following an argument to its conclusion than the loss of one's brain. ${ }^{3}$

\footnotetext{
${ }^{3}$ This research was carried out while holding a Jacobsen Fellowship at the Royal Institute of Philosophy. I am grateful to Tim Crane and Colin Johnston for their comments on earlier drafts.
} 


\section{References}

Olson, E. (2002). What does functionalism tell us about personal identity? Nous (Detroit, Mich.), 36, 682-698. doi:10.1111/1468-0068.00407.

Olson, E. (2003). An argument for animalism. In R. Martin \& J. Barresi (Eds.), Personal identity (pp. 318-334). Oxford: Blackwell.

Shoemaker, S. (1980/2003). Causality and properties. Reprinted in his Identity, cause, and mind: Expanded edition. Oxford: Oxford University Press. Originally printed in Peter van Inwagen (Ed.) Time and cause. Dordrecht: D. Reidel Publishing Co., 1980.

Shoemaker, S. (1999a). Self, body, and coincidence. Proceedings of the Aristotelian Society, 73, 287306.

Shoemaker, S. (1999b). Eric Olson: The human animal. Nous (Detroit, Mich.), 33, 496-504. doi:10.1111/ 0029-4624.00166.

Shoemaker, S. (2003). Realization, micro-realization, and coincidence. Philosophy and Phenomenological Research, 67, 1-23. doi:10.1111/j.1933-1592.2003.tb00023.x.

Shoemaker, S. (2004). Functionalism and personal identity-A reply. Nous (Detroit, Mich.), 38, 525-533. doi:10.1111/j.0029-4624.2004.00481.x.

Shoemaker, S. (2008). Persons, animals and identity. Synthese, 162, 313-324. doi:10.1007/s11229007-9253-y.

Snowdon, P. (1990). Persons, animals, and ourselves. In C. Gill (Ed.), The person and the human mind (pp. 83-107). Oxford: Clarendon Press. 